\title{
FREQUENCY AND SEVERITY OF ACUTE KIDNEY INJURY IN PATIENTS AFTER REPLACEMENT OF LARGE JOINTS WITH INFECTIOUS COMPLICATIONS
}

\author{
Zhidkova O.V. ${ }^{1}$, Lebedeva M.N. ${ }^{1}$, Pervukhin S.A. ${ }^{1}$, Ivanova E.Yu. ${ }^{1}$, Elistratov A.A. ${ }^{1}$, \\ Statsenko I.A. ${ }^{1}$, Palmash A.V. ${ }^{1}$ \\ ${ }^{1}$ Novosibirsk Research Institute of Traumatology and Orthopaedics n.a. Ya.L. Tsivyan, Novosibirsk, e-mail: \\ niito@niito.ru
}

Aims.

To identify the incidence and severity of acute kidney injury (AKI) in patients after replacement of large joints with infectious complications.

Materials and methods.

The object of study: 54 patients with infectious complications after replacement of large joints. The severity of AKI was determined by the RIFLE classification. Three groups of observation were singled out: I - 18 patients $(33.3 \%)$ with AKI in stage R (risk); II - 11 patients (20.3\%) with AKI in stage I (injury); III - 25 patients $(46.3 \%)$ with AKI in stage $F$ (failure). AKI developed in $0.2 \%$ of cases.

Results.

In most cases, the clinical picture of AKI developed 2-4 days after surgery, and 2-5 days after onset of AKI, the signs of infectious endotoxicosis with the development of various infectious complications were noted. The analysis of the intraoperative period established that most patients in groups II and III had hypotension with MBP [mean blood pressure] $55-70 \mathrm{~mm} \mathrm{Hg}, 87.5 \%$ of patients with intraoperative blood loss greater than $20 \%$ of blood volume were included in the study groups II and III. The calculation of odds ratios (OR) showed that low MBP levels, intraoperative blood loss greater than $20 \%$ of blood volume and sepsis are statistically significant factors of the risk of severe AKI $(\mathbf{p}<0.05)$.

Conclusions.

Risk factors for the development of AKI and its severity after replacement of large joints were the presence of arterial hypertension, MBP level of less than $75 \mathrm{~mm} \mathrm{Hg}$, blood loss greater than $20 \%$ of blood volume, and sepsis. Manifestation of the clinical picture of AKI after such operations may be a warning sign of the development of postoperative infection and sepsis.

Keywords: replacement of large joints, acute kidney injury, purulent-septic complications, sepsis, continuous renal replacement therapy, septic shock.

\section{INTRODUCTION.}

Acute kidney injury (AKI) is one of the most severe post-surgery complications that directly correlates with the fatality rates at intensive care units $[1,2]$. Kidney Disease: Improving Global Outcomes (KDIGO) of 2012 was an international consortium dedicated to AKI that defined this acute pathology as a renal dysfunction of varying severity, from insignificant dysfunction to the end stage of kidney disease that would require urgent renal replacement therapy (RRT) [3].

The most frequent causes are: any condition that leads to a reduction in the perfusion pressure in critical organs (shocks accompanied by reduced cardiac output); relative and absolute hypovolemia; obstructive renal disease; nephrotoxic drugs; use of X-ray contrasts. Abnormal perfusion pressure in such conditions is associated with disrupted intrarenal circulation with microcirculation ischemia. Renal hypoxia induces a complex cascade of metabolic and inflammatory processes that lead to bioenergetic disadaptation of cells, which manifests itself in the severity and duration of AKI [4]. However, AKI is mostly analyzed as part of sepsis-associated multiorgan failure [4].

The commonly known diagnostic markers for AKI are serum creatinine levels, diuresis volume and rate. As of today, there are papers on the efficiency of new serum-carried AKI 
biomarkers, e.g. NGAL or neutrophil gelatinase-associated lipocalin [5]. However, this test is not yet available for day-to-day AKI diagnosis.

Recent studies found AKI in $67 \%$ of intensive care (IC) patients. R-class (risk) AKI was found in $12 \%$, I-class in $27 \%$, and F-class (failure) in $28 \%$. AKI would progress, with $56 \%$ degrading from R to I or F; severe AKI that required urgent RRT was observed in 5\% IC patients [6]. When using the published consensus criteria (the RIFLE criteria), AKI is diagnosed in nearly $8 \%$ inpatients and in $>50 \%$ IC patients [6].

There are a few international studies on renal dysfunction from the perspectives of traumatology and orthopedics [7, 8]. However, there are too few papers on AKI development in patients that have undergone major joint replacement [9]. Such replacements have a number of known complications: deep vein thrombosis in lower limbs, pulmonary embolism (PE), endoprosthesis displacement, surgical site infection, and AKI $[10,11]$. The latter can prolong the hospital stay and increase the fatality rates, especially for patients that have comorbidities such as diabetes mellitus, chronic kidney disease (CKD), arterial hypertension (AH), cardiovascular pathology, and obesity [11]. Besides, there is substantial proof that in at least $50 \%$ of all cases, it is sepsis and septic shock that cause AKI in IC patients [12]. Despite the ever better life support, septic AKI occurrence and fatality rates remain high [12].

This is where the research goal came from: to find the occurrence rates and severity of acute kidney injury in cases of inflection-complicated major joint replacements.

MATERIALS AND METHODS. The research team retrospectively analyzed medical records on major joint replacements in 23,177 patients from 2010 to 2016. For this research, the team selected 54 patients with postoperative complications and AKI. Patients were aged $67.9 \pm 8.0$ on average, 32 women and 22 men. Twenty-eight (51.9\%) of them had primary hip replacement while $12(22.2 \%)$ had primary knee replacement. Ten patients (18.5\%) had repeated hip replacement, and $4(7.4 \%)$ had repeated knee replacement.

The inclusion criteria were diagnosed postoperative AKI and postoperative infectious complications. No exclusion criteria. Patients were grouped by AKI severity.

The RIFLE classification (KDIGO Acute Injury Workgroup, 2013) was used to determine the severity of AKI, see Table 1 .

Table 1

RIFLE criteria (KDIGO Acute Kidney Injury Workgroup, 2013)

\begin{tabular}{|l|c|l|}
\hline \multicolumn{1}{|c|}{ Stage } & \multicolumn{1}{c|}{ GFR } & \multicolumn{1}{c|}{ Diuresis rate } \\
\hline Risk R & $\begin{array}{r}1.5 \times \text { blood creatinine concentration or } \\
\text { GFR reduction by }>25 \% \text { of the initial value }\end{array}$ & $\begin{array}{l}<0.5 \mathrm{ml} / \mathrm{kg} / \mathrm{h} \\
\text { over } 6 \mathrm{hours}\end{array}$ \\
\hline Injury I & $\begin{array}{r}2 \times \text { blood creatinine concentration or } \\
\text { GFR reduction by }>50 \% \text { of the initial value }\end{array}$ & $\begin{array}{l}<0.5 \mathrm{ml} / \mathrm{kg} / \mathrm{h} \\
\text { over } 12 \mathrm{~h}\end{array}$ \\
\hline
\end{tabular}




\begin{tabular}{|l|c|c|}
\hline Failure F & $\begin{array}{c}3 \times \text { blood creatinine concentration or } \\
\text { GFR reduction by }>50 \% \text { of the initial value or } \\
\text { increase to } \geq 354 \mu \mathrm{mol} / 1 \text { with rapid growth to } \geq \\
44 \mu \mathrm{mol} / 1\end{array}$ & $\begin{array}{c}<0.3 \mathrm{ml} / \mathrm{kg} / \mathrm{h} \text { over } \\
24 \mathrm{~h} \text { or } 12-\mathrm{h} \text { anuria }\end{array}$ \\
\hline Loss & $\begin{array}{c}\text { Complete loss of kidney function } \\
\geq 4 \text { weeks }\end{array}$ & $\begin{array}{c}\text { months } \\
\text { End }\end{array}$ \\
\hline
\end{tabular}

Three groups were identified based on the AKI severity:

Group I of 18 patients (33.3\%) with Stage R AKI;

Group II of 11 patients (20.3\%) with Stage I AKI;

Group III of 25 patients (46.3\%) with Stage F AKI.

The research team collected and analyzed the following data: age, sex, body mass index (BMI), presence or absence of arterial hypertension (AH) and diabetes mellitus (DM), intake of non-steroid anti-inflammatory drugs (NSAIDs) and analgesics, and presence of chronic kidney disease (CKD), see Table 2. As shown in Table 2, the groups were comparable in the core features.

Analysis of the intraoperative period drew into consideration the factors that, as the authors believed, were likely to strongly affect the course of AKI: the duration of surgery, the type of anesthesia, the blood loss, the mean ABP (ABPm), whether blood transfusion was performed, whether vasopressor or inotropic support was involved, whether bone cement was used, see Table 4.

Table 2

Description of patient groups

\begin{tabular}{|c|c|c|c|l|}
\hline \multirow{2}{*}{ Features } & \multicolumn{3}{|c|}{ Groups } & \multicolumn{1}{c|}{ P- } \\
\cline { 2 - 5 } & I & II & III & (Kruskal- \\
\hline
\end{tabular}




\begin{tabular}{|l|l|l|l|l|l|}
\hline \multicolumn{2}{|l|}{} & & & & Wallis \\
\hline \multicolumn{2}{|c|}{ Age } & $70.2 \pm 9.0$ & $67.3 \pm 9.0$ & $66.4 \pm 12.2$ & 0.535 \\
\hline \multirow{3}{*}{ Sex } & F & $10(55.5 \%)$ & $5(45.5 \%)$ & $15(60.0 \%)$ & 0.2 \\
\cline { 2 - 5 } & & & & \\
\hline \multicolumn{2}{|c|}{ BMI } & $8(44.45 \%)$ & $6(54.5 \%)$ & $10(40.0 \%)$ & \\
\hline \multicolumn{2}{|c|}{ DM } & $30.6 \pm 7.6$ & $31.5 \pm 5.7$ & $31.9 \pm 7.8$ & 0.83 \\
\hline \multicolumn{2}{|c|}{ AH } & $1(5.5 \%)$ & $1(9.0 \%)$ & $4(16.0 \%)$ & 0.1 \\
\hline \multicolumn{2}{|c|}{ NSAI } & $14(77.8 \%)$ & $11(100.0 \%)$ & $23(92.0 \%)$ & 0.01 \\
\hline \multicolumn{2}{|c|}{ Tramadol } & $13(72.2 \%)$ & $8(72.7 \%)$ & $22(88.0 \%)$ & 0.2 \\
\hline \multicolumn{2}{|c|}{ CKD } & $5(27.7 \%)$ & $3(27.3 \%)$ & $3(12.0 \%)$ & 0.3 \\
\hline
\end{tabular}

All patients were given standard preventive antibiotic treatment with 3rd-gen cephalosporins. Vancomycin was prescribed if the medical history indicated intolerance to penicillins. Linezolid was prescribed to CKD patients as vancomycin is nephrotoxic. The research team monitored the blood creatinine levels (before surgery, as well as Days 1, 2, and 3 after surgery) and the hourly diuresis rate.

Intraoperative fluid replacement volumes and rates were determined by the patient's hemodynamic status on top of sympathetic blockade and blood loss volume. The fluid replacement volumes were calculated based on the patient's physiological need for fluids and the current blood loss through wound drainage.

Statistical processing was performed in Statistica for Windows 6.0. Student's t-test used for significance testing for normally distributed parameters, the Kruskal-Wallis test otherwise. Groups were compared qualitatively by the odds ratio. For (approximately) normal distribution, data was represented as $\mathrm{M} \pm \mathrm{SD}$, where $\mathrm{M}$ is the arithmetic mean, $\mathrm{SD}$ is the standard deviation. The difference was deemed significant at $p<0.05$.

The study protocol followed guidelines for experimental investigation with human subjects in accordance with the Declaration of Helsinki and was approved by the ethics committee. Written informed consent was obtained from each patient (or an official representative) before the study.

RESULTS. Compared to data from other authors, this study revealed a relatively low AKI occurrence rate of $0.2 \%$ after major lower limb joint replacements. For comparison: Helene Peregaard et al. [9] identified AKI in $2 \%$ of patients that had undergone major joint replacement; Parvizi et al. [7] did a prospective study of 1,636 patients that had undergone primary major joint replacement, which found an indicated rate of $0.85 \%$.

All patients stayed in the IC unit after surgery until the next morning, and then were transferred to the specialized unit. Two patients (11.1\%) of Group I remained in the ICU for further monitoring and treatment as they showed clinical signs of AKI. Two patients also showed AKI signs on Day 1 and had to stay in the ICU in both Group II and Group III, where they accounted for $18.2 \%$ and $8.0 \%$ of the group, respectively. 
In most cases, clinical signs of AKI appeared on Day 2 to 4 after surgery, and the patients had to be transferred from their specialized units back to the ICU. These were $16(88.9 \%)$ patients in Group I, 9 (81.8\%) in Group II, and 23 (92.0\%) in Group III. In general, patients only entered the ICU with clinical signs of prerenal AKI on top of arterial hypotension and hypovolemia: 14 (78\%) in Group I, 6 (54.5\%) in Group II, and 15 (60\%) in Group III. Note that in all the specified clinical cases, infectious endotoxicosis with various infectious complications emerged on Days 2 to 5 after the AKI onset. Apparently, AKI manifested before the clinical signs of an infectious process in 35 $(64.8 \%)$ patients.

A different situation was observed in some other clinical cases: 3 Group I patients transferred to the ICU had AKI as part of the multiple organ dysfunction syndrome on top of an apparent infectious process; in Group II, 5 (45.4\%) patients had infections in multiple organs and systems. A similar clinical situation was observed in 10 (40.0\%) Group III patients. Table 3 summarizes the infectious complication data.

Table 3

Infectious complications in the study groups

\begin{tabular}{|l|l|l|l|c|}
\hline \multirow{2}{*}{ Injection } & \multicolumn{3}{|c|}{ Groups } & \multirow{2}{*}{$\begin{array}{c}\text { P- } \\
\text { test } \\
\text { (Kruskal- } \\
\text { Wallis })\end{array}$} \\
\cline { 2 - 4 } & \multicolumn{1}{|c|}{$\begin{array}{c}\text { I } \\
(\mathrm{n}=18)\end{array}$} & \multicolumn{1}{|c|}{$\begin{array}{c}\text { II } \\
(\mathrm{n}=11)\end{array}$} & $\begin{array}{c}\text { III } \\
(\mathrm{n}=25)\end{array}$ & 1.0 \\
\hline Wound infection & $7(38.8 \%)$ & $3(27.2 \%)$ & $8(32.0 \%)$ & 1.0 \\
\hline Pneumonia & $3(16.6 \%)$ & $2(18.2 \%)$ & $3(12.0 \%)$ & 0.9 \\
\hline $\begin{array}{l}\text { Urinary tract } \\
\text { infection }\end{array}$ & $5(27.7 \%)$ & $2(18.2 \%)$ & $4(16.0 \%)$ & 0.011 \\
\hline Sepsis & $2(11.4 \%)$ & $7(63.6 \%)$ & $12(48.0 \%)$ & 0.9 \\
\hline
\end{tabular}

According to the latest literature, prerenal factors and sepsis cause the most cases of AKI, which is consistent with the data presented herein. Intergroup comparison in terms of infectious complications revealed significant difference for sepsis only. Sepsis was found in 21 (38.9\%) AKI patients. Twelve patients $(22.2 \%)$ had a septic shock. Two (3.7\%) patients with severe AKI required continuous renal replacement therapy based on their renal and extrarenal indications (septic shock and ARDS). Four patients died: 3 (12\%) in Group III and 1 (9.0\%) in Group II.

Consider the factors that were most likely to affect the course of AKI. Table 4 summarizes the key features of the performed surgeries.

Table 4.

Key features of the performed surgeries in the patient groups

\begin{tabular}{|l|r|r|r|c|}
\hline \multicolumn{1}{|c|}{ Feature } & I & II & III & $\begin{array}{c}\text { test } \\
\text { (Kruskal- } \\
\text { Wallis) }\end{array}$ \\
\hline Duration of surgery (min) & $74.4 \pm 23.9$ & $77.3 \pm 24.0$ & $65.0 \pm 32.0$ & 0.5 \\
\hline General anesthesia & 0 & $2(18.1 \%)$ & $3(12.0 \%)$ & 0.8 \\
\hline Regional anesthesia & $16(88.9 \%)$ & $7(63.8 \%)$ & $21(84.0 \%)$ & 0.8 \\
\hline
\end{tabular}




\begin{tabular}{|c|c|c|c|c|}
\hline Combined anesthesia & $2(11.1 \%)$ & $2(18.1 \%)$ & $1(4.0 \%)$ & 0.8 \\
\hline $\mathrm{ABPm}, \mathrm{mmHg}$ & $\begin{array}{c}89.5 \pm 16.8 \\
\mathrm{P}_{\mathrm{I}-\mathrm{II}}<0.05 \\
\mathrm{P}_{\text {I-III }}<0.05\end{array}$ & $\begin{array}{r}74.7 \pm 14.7 \\
\mathrm{P}_{\mathrm{I}-\mathrm{II}}<0.05 \\
\mathrm{P}_{\text {III-III }}>0.05\end{array}$ & $\begin{array}{c}74.8 \pm 16.1 \\
\mathrm{P}_{\text {III-I }}<0.05 \\
\mathrm{P}_{\text {III-II }}>0.05\end{array}$ & 0.01 \\
\hline Vasopressor support & $3(16.6 \%)$ & $6(54.5 \%)$ & $6(24.0 \%)$ & 0.08 \\
\hline $\begin{array}{l}\text { Blood loss of more than } 20 \% \text { of } \\
\text { BV }\end{array}$ & $1(5.5 \%)$ & $2(18.0 \%)$ & $5(20.0 \%)$ & 0.01 \\
\hline Blood transfusion performed & $\begin{array}{r}1(5.5 \%) \\
\mathrm{P}_{\text {I-II }}<0.05 \\
\mathrm{P}_{\mathrm{I}-\mathrm{III}}<0.05\end{array}$ & $\begin{array}{c}4(36.3 \%) \\
P_{\text {II-I }}<0.05 \\
P_{\text {I-IIII }}<0.05\end{array}$ & $\begin{array}{c}9(36.0 \%) \\
P_{\text {III-I }}<0.05 \\
P_{\text {III-II }}>0.05\end{array}$ & 0.01 \\
\hline Bone cement used & $2(11.0 \%)$ & $4(36.3 \%)$ & $5(20.0 \%)$ & 1.0 \\
\hline
\end{tabular}

As shown in Table 4, no difference between groups was observed in terms of surgery duration, the anesthesia method, intraoperative vasopressor support, or bone cement use. However, a statistically significant difference was identified in terms of mean arterial blood pressure, intraoperative blood loss, or blood transfusion.

In Group I, most patients (15 or $83.3 \%$ ) had ABPm of 75 to $100 \mathrm{mmHg}$, while only 3 $(27.3 \%)$ in Group II and 11 (44\%) in Group III had normal blood pressure. Other patients had ABPm of 55 to $70 \mathrm{mmHg}$, which meant low ABPm could be considered a risk factor for severe postoperative AKI. This is consistent with the data of other researchers that consider hypotension a significant independent AKI development factor and demonstrate the correlation of its duration and severity with the AKI severity [13].

Blood loss in excess of $20 \%$ BV was noted in $5.5 \%$ of Group II patients, $18.2 \%$ of Group II patients and $20 \%$ of Group III patients. As shown in the data, most (87.5\%) of patients with intraoperative operative blood loss in excess of $20 \%$ BV were in Groups II and III.

Fifteen patients $(27.8 \%)$ required blood transfusion, of whom $93.3 \%$ ended up in severe AKI groups. In terms of blood transfusion requirement, Groups I and II, I and III differed significantly, while Groups II and III did not. The literature review did not reveal any papers where blood loss would be considered an AKI risk factor. The fact that the blood loss volume and rate correlate directly to hypotension, which is considered an independent AKI development factor, is also important.

Patients' premorbid data were analyzed to find AKI predictors.

Sixty-six percent of them were found to have previously had CKD. Peregaard et al. [9] dwell upon how CKD affects the clinical outcomes in orthopedics; their study identified a statistically significant increase in AKI occurrence rates and severity in patients who initially had CKD. The present study did not identify statistically significant differences by this feature between the groups.

Numerous papers find that advanced age is an independent AKI risk factor [4, 7]. However, Sharrock et al. [14] do not believe so. Neither does this study support that idea.

Some papers point out that high BMI is an independent AKI risk and severity factor [15]. Although the patients covered herein varied broadly in terms of BMI, ranging from 25 to 46 , this 
study does not confirm such finding.

Belmont et al. [7] found that high risk and severity of AKI after major joint replacement independently correlated with diabetes mellitus in patients. The present study did not identify such correlations.

Some authors recognize arterial hypertension as an AKI risk factor. Most likely, it is important that patients with high initial systolic and diastolic blood pressure are less capable of sustaining blood pressure drops during anesthesia induction or in the case of the sympathetic blockade [13]. This paper clearly shows that all the patients covered herein had arterial hypertension as an independent disease, and most ended up in severe AKI groups, see Table 2.

Let us use the odds ratio (OR), i.e. the ratio of factor observation rates in severe AKI groups to that in the Stage R group, to find the severe AKI risk predictors, see Table 5. As shown in Table 5, it is low ABPm and significant blood loss, as well as sepsis, that should be considered AKI predictors.

Table 5

Severe AKI predictors

\begin{tabular}{|c|c|l|}
\hline Severe AKI risk factor & Odds ratio, CI 95\% & $\mathrm{p}$ \\
\hline $\mathrm{CKD}$ & $1.5(0.123$ to 1,644$)$ & 0.6 \\
\hline $\mathrm{AH}$ & $4.8(0.797$ to 29.6$)$ & 0.3 \\
\hline $\mathrm{DM}$ & $2.72(0.296$ to 25.425$)$ & 0.7 \\
\hline $\mathrm{ABPm}<75 \mathrm{mmHg}$ in excess of & $7.8(1.9$ to 32$)$ & $<0.05$ \\
\hline $\begin{array}{l}\text { Intraoperative } \\
\text { 20\% BV lood }\end{array}$ & $9.6(1.4$ to 80$)$ & $<0.05$ \\
\hline Sepsis & $8.971(1.789$ to 44.689$)$ & $<0.05$ \\
\hline
\end{tabular}

\section{CONCLUSIONS.}

1. AKI had an incidence of $0.2 \%$ after major joint replacements with infectious complications, with severe AKI being prevalent.

2. Risk- and severity-defining factors are: arterial hypertension, ABPm below 75 $\mathrm{mmHg}$, blood loss > 20\% BV, and sepsis.

3. The manifestation of clinical AKI signs after major joint replacement might be a precursor of postoperative infectious process and sepsis.

\section{FINANCIAL SUPPORT AND SPONSORSHIP}

Nil.

\section{CONFLICTS OF INTEREST}

The authors declare no conflict of interest 


\section{REFERENCES}

1. Sokolov D.V., Polushin Iu.S. Acute renal injury in the peri-operative period [Ostroe pochechnoe povrezhdenie $\mathrm{v}$ perioperatsionnom periode]. Messenger of anesthesiology and resuscitation Vestnik anesteziologii i reanimatologii, 2018, vol. 15, no 1, pp. 46-54, doi 10.21292/2078-56582018-15-1-46-54.

2. Liotta M., Olsson D., Sartipy U. et al. Minimal changes in postoperative creatinine values and early and late mortality and cardiovascular events after coronary artery bypass grafting. The American Journal of Cardiology, vol. 113, no.1, pp. 70-75, doi 10.1016/j.amjcard.2013.09.012.

3. Bellomo R., Ronco C., Kellum J.A. et al. Acute renal failure - definition, outcome measures, animal models, fluid therapy and information technology needs: The Second International Consensus Conference of the Acute Dialysis Quality Initiative (ADQI) Group. Critical Care, 2004. vol. 8, pp. 204-212.

4. Zarbock A., Gomez H., Kellum J.A. Sepsis-induced acute kidney injury revisited: pathophysiology, prevention and future therapies, Current Opinion in Critical Care, 2014, vol. 20, pp. 588- 595, doi 10.1097/mcc.0000000000000153.

5. Vijayan A., Faubel S., Askenazi D.J. et al. Clinical use of the urine biomarker [TIMP-2] [IGFBP7] for acute kidney injury risk assessment. American Journal of Kidney Diseases, 2016, vol. 68, p. 1928.

6. Hoste E. A., Bagshaw S. M., Bellomo R. et al. Epidemiology of acute kidney injury in critically ill patients: the multinational AKI-EPI study. Intensive Care Medicine, 2015, vol. 41, pp. 1411-1423.

7. Belmont Jr. PJ., Goodman G.P., Waterman B.R. et al. Thirty-day postoperative complications and mortality following total knee arthroplasty: incidence and risk factors among a national sample of 15,321 patients. The Journal of Bone and Joint Surgery-American, 2014, vol. 96. no. 1, pp. 20-26, doi 10.2106/jbjs.m.00018.

8. Parvizi J., Mui A., Purtill J.J. Total joint arthroplasty: when do fatal or near-fatal complications occur? The Journal of Bone \& Joint Surgery, 2007, vol. 89, no. 1, pp. 27-32, doi 10.2106/jbjs.e.01443.

9. Peregaard H., Damholt M.B., Solgaard S. et al. Renal function after elective total hip replacement Incidence of acute kidney injury and prevalence of chronic kidney disease. Acta Orthopaedica, 2016, vol. 87, no. 3, pp. 235-238, doi 10.3109/17453674.2016.1155130.

10. Kane P., Chen C., Post Z et al. Seasonality of infection rates after total joint arthroplasty. Orthopedics, 2014, vol. 37, no. 2, pp. 182-186, doi 10.3928/01477447-20140124-23.

11. Hassan B.K., Sahlström A., Dessau R.B. Is there a risk of permanent renal dysfunction after primary total hip and knee joint replacements? Journal of Orthopaedic Surgery and Research. 2015, vol. 10, no 1, p.158, doi 10.1186/s13018-015-0299-0.

12. Kellum J.A., Chawla L.S., Keener C. et al. The effects of alternative resuscitation strategies on acute kidney injury in patients with septic shock. American Journal of Respiratory and Critical 
Care Medicine, 2016, vol. 193, no 3, pp. 281-287, doi 10.1164/rccm.201505-0995oc.

13. Sun L.Y., Wijeysundera D.N., Tait G.A. et al. Association of intraoperative hypotension with acute kidney injury after elective noncardiac surgery. Anesthesiology. 2015, vol. 123, no 3, pp. 515-523, doi 10.1097/aln.0000000000000765.

14. Sharrock N.E., Cazan M.G., Hargett M.J. et al. Changes in mortality after total hip and knee arthroplasty over a ten-year period. Anesthesia \& Analgesia, 1995. vol. 80, no. 2, pp. 242-248, doi 10.1097/00000539-199502000-00008.

15. Suleiman L.I., Ortega G, Ong'uti S.K. et al. Does BMI affect perioperative complications following total knee and hip arthroplasty? Journal of Surgical Research, 2012, vol. 174, no. 1, pp. 7-11, doi 10.1016/j.jss.2011.05.057. 